\title{
Consumers' behaviour regarding the use of expiry dates on food packages
}

\author{
T. Avermaete ${ }^{1,2}$, R. Roest, E. Mathijs ${ }^{1}$ and L. Vranken ${ }^{1}$ \\ ${ }^{1}$ Division of Bio-Economics, Department of Earth and Environmental Sciences, KU Leuven, Belgium and ${ }^{2}$ Department \\ Health \& Technology, Katholieke Hogeschool Leuven, Belgium
}

Food waste is a key issue on the European agenda. Considering the entire food chain, European citizens waste yearly $95-115 \mathrm{~kg}$ food per person ${ }^{(1)}$. Consumers thereby account for $42 \%$ of total food waste ${ }^{(2)}$. Both from an environmental point of view and economically, food waste needs to be reduced ${ }^{(3)}$. Moreover, given the fact that almost one billion people worldwide suffer from hunger, current food waste cannot be justified. One of the questions raised concerns the need for expiry dates on food products. The debate relies on the fact that a considerable amount of food is thrown away because the expiry date is reached even though the food is still suitable for consumption.

The purpose of this research is (1) to identify consumers' behaviour with respect to the use of the expiry date of food when doing purchases and when actually consuming the food at home and, (2) to analyse how the consumers' socio-demographic characteristics and the type of food affect the use of the expiry data.

A standardised questionnaire was developed to measure consumers' behaviour regarding the use of expiry dates on food packages. In addition, we asked for socio-demographic and economic characteristics of the respondents as well as for attitudes concerning food consumption, environmental concerns and risk behaviour. The research was carried out in Flanders; the sample included 120 households.

Overall, $68 \%$ of the respondents claim to check the expiry date in the shop. Only $6 \%$ seldom or never check this information. Similar figures were obtained for the use of the expiry date before consumption at home. $43 \%$ of the respondents check the expiry date before consumption and will throw away food that has been expired, while only 14\% claims they seldom or never throw away expired food unless they observe a change in the physical appearance of the product. Regression analysis shows that several characteristics are determining consumer behaviour regarding the use of the expiry date. Most pronounced are the impact of age, large family size, risk behaviour and overall environmental concern.

The conclusion of this research is twofold. On the one hand, the results clearly indicate the need to consider different food groups in the debate on using expiry dates as a means to reduce food waste. On the other hand, the regression analysis shows that the use of expiry date depends on socio-demographic characteristics of consumers as well as on other characteristics related to waste behaviour. Based on further data obtained in this survey, research will be carried out on the option of replacing the expiry date by a description.

1. Gustavsson J, Cederberg C, Sonesson U, van Otterdijk R, Meybeck A (2011) Global food losses and food waste, extent, causes and prevention. Study conducted for the International Congress SAVE FOOD! at Interpack 2011 Düsseldorf, Germany. FAO.

2. European Commission (2010) Being wise with waste: the EU's approach to waste management. Report of European Commission.

3. Koivupuro H-K, Hartikainen H, Silvennoinen K, Katajajuuri J-M, Heikintalo N, Anu Reinikainen A \& Jalkanen L (2012) International Journal of Consumer Studies 36, 183-191. 